\title{
Prospective evaluation of quality of life 54 months after high-dose intensity-modulated radiotherapy for localized prostate cancer
}

\author{
Aurore Goineau ${ }^{1 \dagger}$, Virginie Marchand ${ }^{1 \dagger}$, Jérome Rigaud ${ }^{2}$, Sylvain Bourdin ${ }^{1}$, Emmanuel Rio ${ }^{1}$, Loic Campion ${ }^{1}$,
} Angélique Bonnaud-Antignac ${ }^{1,3}$, Marc-André Mahé ${ }^{1}$ and Stéphane Supiot ${ }^{{ }^{*}}$

\begin{abstract}
Objective: To determine late toxicity and quality of life (QoL) in patients with localized prostate cancer after highdose intensity-modulated radiotherapy (IMRT).

Patient and methods: This was a prospective study in patients with localized prostate adenocarcinoma who had been treated by IMRT (76 Gy) between February and November 2006. Physicians scored acute and late toxicity using the Common Terminology Criteria for Adverse Events (version 3.0). Patients completed cancer and prostatespecific QoL questionnaires (EORTC QLQ-C30 and QLQ-PR25) before IMRT (baseline) and at 2, 6, 18 and 54 months.

Result: Data were available for 38 patients (median age, 73 years) (18\% low risk; 60\% intermediate risk; 32\% high risk). The incidence of urinary and gastrointestinal toxicity was respectively: immediately post IMRT: $36.8 \%$ and $23.7 \%$ (grade 1), 5.3\% and 5.3\% (grade 2), 2.6\% and $0 \%$ (grade 3); at 18 months: $23.7 \%$ and $10.3 \%$ (grade 1), $26.3 \%$ and 13.2\% (grade 2), $0 \%$ and 2.6\% (grade 3); at 54 months: $34.2 \%$ and $23.7 \%$ (grade 1), 5.3\% and 15.8\% (grade 2), 5.3\% and $0 \%$ (grade 3). At 54 months, significant worsening was reported by patients for $11 / 19 \mathrm{QoL}$ items but the worsening was clinically relevant (>10 points) for 7 items only: physical, role as well as social functioning, fatigue, pain, dyspnoea and constipation. There was no significant difference between 54-month and baseline QoL scores for global health, gastrointestinal symptoms, treatment-related symptoms and sexual function. However, there was significant - but clinically non-relevant ( $<10$ points) - worsening of urinary symptom.
\end{abstract}

Conclusion: High-dose IMRT to the prostate with accurate patient positioning did not induce any clinically relevant worsening in late urinary and gastrointestinal QoL at 54 months. Impaired physical and role functioning may be related to age and comorbidities.

Keywords: Prostate cancer, IMRT, Quality of life

\section{Introduction}

In patients with localized prostate cancer and a good prognosis, the efficacy of external beam is similar to that of surgery or brachytherapy [1-3]. Adjuvant hormonal therapy is often offered to patients with an intermediate or poor prognosis [3]. However, over recent years, radiotherapy (RT) has seen major advances such as the introduction of 3D conformal RT (3D-CRT) and, more

\footnotetext{
* Correspondence: stephane.supiot@ico.unicancer.fr

${ }^{\dagger}$ Equal contributors

'Integrated Center of Oncology René Gauducheau, Nantes-St Herblain, France

Full list of author information is available at the end of the article
}

recently, intensity-modulated radiation therapy (IMRT) and image-guided RT (IGRT) [4,5].The higher radiation doses that can be delivered to the prostate by these new techniques, whilst sparing at-risk organs, has improved progression-free survival and reduced acute and late toxicities [6-13].

Quality of life (QoL) is a key criterion in the choice of treatment for early prostate cancer but is difficult to assess despite the availability of validated questionnaires [14-16]. Studies tend to be retrospective [17]. Long-term QoL after IMRT has received attention in a limited number of prospective studies $[18,19]$ even though adverse effects are known to occur late (over 30 months) [20,21].

\section{Biomed Central}


In 2006, we initiated a prospective study of the toxicity and QoL associated with high-dose IMRT for localized prostate cancer. Results for 18 months of follow-up have been published [22]. We now describe longer term results (54 months) to confirm good tolerance of this treatment after a long-term follow-up.

\section{Patients and methods}

This prospective study was performed in the Radiotherapy Department of the "Integrated Center of Oncology René Gauducheau" and included all consecutive patients with localised prostate cancer who were eligible for IMRT without nodal irradiation between February and December 2006. Absence of lymph node invasion was established by laparoscopic lymphadenectomy in patients with a $>10 \%$ risk of invasion according to Partin's tables [23]. Absence of bone metastases was established by bone scintigraphy.

The 5-field IMRT technique delivering a dose of 76 Gy in 38 fractions to the prostate and delineation of organ-at-risk contour limits and constraints have been described in an earlier publication [22]. The percent organ-at risk volume receiving 65 Gy (V65) was derived from dose-volume histograms for bladder and rectal tissue. Patient positioning was checked daily [24].

Patients at intermediate risk of relapse according to D'Amico's classification [1] received concurrent adjuvant hormonal therapy with an LHRH analogue for 3 to 6 months. Treatment was continued for 2 to 3 years in high-risk patients.

Physicians scored treatment toxicity (general, urinary, gastrointestinal (GI) and sexual) using the Common Terminology Criteria for Adverse Events (CTCAE) toxicity scale (version 3.0) immediately after IMRT (acute toxicity) and at subsequent visits (6,18 and 54 months). Patients completed the core and prostate cancerspecific modules of the EORTC QoL questionnaires (QLQ-C30 version 3.0 and QLQ-PR25) at their pretreatment and post-treatment visits (months 2, 6, 18 and 54). Items were combined into several scales (from 1 to 100) according to EORTC rules. For the global health and function scales, a high score signalled a better QoL; for the symptom scales, a high score was indicative of a poorer QoL.

Changes in toxicity and QoL over time were analyzed by the Wilcoxon signed-rank test. Correlations between toxicity and clinical or dosimetric variables were sought using the Mantel-Haenszel test for linear association (categorical variables) or the Spearman correlation coefficient (continuous variables). A difference from baseline was considered statistically significant if the $\mathrm{p}$ value was $<0.01$ and clinically relevant if the difference was $>10$ points, as per Osoba interpretation of EORTC criteria [25-27]. Factors that might predict QoL were tested by the
Kruskal-Wallis test (categorical variables) or the Spearman correlation coefficient (continuous variables).

\section{Results}

From February to November 2006, 55 consecutive patients with localized prostate cancer underwent IMRT. The characteristics of the 38 patients with data for analysis at 54 months are given in Table 1 . The remaining 17 patients were broken down as follows: 5 deaths from causes other than prostate cancer, one case of Alzheimer's disease and 3 cases of advanced cancer other than prostate cancer (rectum, lung, Vater's ampulla) precluding completion of the questionnaires, 3 refusals to complete the questionnaire at 54 months, and 5 lost to follow-up.

Median age at baseline was 73 years (range 54-80). Among the 55 patients, 25 (45.5\%) had received hormonal therapy: 4 for 3 months, 11 for 6 months, and 10 for 2 to 3 years. The characteristics of the 17 loss to followup patients were very similar to those of the 38 analysable patients at 54 months in terms of median age (73), initial D'Amico's classification (47\% low risk, 24\% intermediate and 29\% high risk) and acute asthenia (59\% mostly grade 1 at $41 \%$ ), urinary toxicity (53\% grade 1 and $35 \%$ grade 2 ) and bowel toxicity (24\% grade 1 and $12 \%$ grade 2 ). Among the 38 analysable patients, 29 (76.3\%) were in remission for prostate cancer and 9 (23.7\%) in biochemical relapse whilst on hormonal therapy. Of these 9 patients, 7 (78\%) were high-risk patients according to D'Amico's classification.

Immediately after IMRT, 60.5\% (15/38) patients reported asthenia (39.5\% grade 1$)$. Its incidence decreased to $26.3 \%$ $(10 / 38)$ by 6 months and $7.9 \%(3 / 38)$ by 18 months, but rose to $36.8 \%$ (28.9\% grade 1 ) by 54 months.

Table 1 Patients' characteristics

\begin{tabular}{|c|c|}
\hline Characteristics & n (\%) \\
\hline \multicolumn{2}{|l|}{ Age at diagnosis } \\
\hline$\leq 65$ ans & $9(24 \%)$ \\
\hline $65-80$ ans & $28(74 \%)$ \\
\hline$\geq 80$ ans & $1(2 \%)$ \\
\hline Cardiovascular history & $15(39 \%)$ \\
\hline \multicolumn{2}{|l|}{ Classification risk at diagnosis } \\
\hline low risk & $17(45 \%)$ \\
\hline Intermediate risk & $11(29 \%)$ \\
\hline High risk & $10(26 \%)$ \\
\hline \multicolumn{2}{|l|}{ Cancer status at 54 months } \\
\hline Remission & $29(76 \%)$ \\
\hline Biological relapse & $9(24 \%)$ \\
\hline high risk & $7(18 \%)$ \\
\hline intermediate risk & $1(2 \%)$ \\
\hline low risk & $1(2 \%)$ \\
\hline
\end{tabular}


Physician-assessed urinary and GI toxicity over time is shown in Figure 1. During the last IMRT sessions, most patients suffered from urinary symptoms (52.6\% grade 1 ; $42.1 \%$ grade 2), mainly from dysuria and increased urination frequency. Only one patient experienced grade 3 urinary toxicity and underwent placement of a temporary urinary catheter. Urinary toxicity resolved in 57.9\% patients within 6 months. In the other patients, urinary toxicity was low grade $(34.2 \%$ grade $1 ; 5.3 \%$ grade 2$)$ except for one case $(2.6 \%)$ of grade 3 toxicity. The incidence of urinary toxicity was highly similar at 6 and 18 months (42.1\% and 50\%, respectively) and remained stable until 54 months (44.7\%) (34.2\% grade 1; $7.9 \%$ grade 2) with one patient experiencing grade 3 toxicity. This patient underwent transurethral resection of the prostate (TURP) for dysuria with partial improvement of symptoms.

The reported incidence of GI toxicity immediately after IMRT was $50 \%$ (39.5\% grade $1 ; 10.5 \%$ grade 2$)$. The main symptoms were grade 1 diarrhoea (23.7\%), flatulence (18\% grade $1 ; 8 \%$ grade 2$)$, grade 1 proctitis $(15.8 \%)$ and haemorrhoids $(\mathrm{n}=4(10.5 \%)$ with 2 patients presenting slight rectal bleeding). The incidence decreased to $26.3 \%$ at 6 months, was $28.9 \%$ at 18 months, but rose to $39.5 \%$ (26.3\% grade $1 ; 13.2 \%$ grade 2 ; no grade 3 ) at 54 months. At 54 months, diarrhoea was less frequent $(10.6 \%)$ but had increased to grade 2 in 2 patients $(5.3 \%)$. Flatulence was quite common $(21.1 \%$ grade $1 ; 2.6 \%$ grade 2 ). Grade 1 rectitis and haemorrhoids affected 4 patients (10\%) in each case.

Sexual function was not assessed in all patients at all time points. Only $12 / 38$ patients $(31.6 \%)$ were sexually active immediately after IMRT. Sexual dysfunction was recorded in $24 / 38(63.2 \%)$ of patients at 18 months and $25 / 38(65.8 \%)$ patients at 54 months (64\% grade $1 ; 12 \%$ grade $2 ; 8 \%$ grade 3 ).

In an analysis of predictive factors for late toxicity at 54 months, acute toxicity was not predictive of general late toxicity $(\mathrm{p}=0.52)$ or sexual dysfunction $(\mathrm{p}=0.13)$. However, it was a predictive factor for both late urinary toxicity $(\mathrm{p}=0.0094)$ and late GI toxicity $(\mathrm{p}=0.0213)$. The overall rectal wall was not a predictive factor for late GI toxicity $(\mathrm{p}=0.54)$ but the volume receiving $65 \mathrm{~Gy}(\mathrm{~V} 65)$ or $60 \mathrm{~Gy}$ (V60) was (Table 2). Neither the overall nor V65 bladder wall volumes were predictive factors for late urinary toxicity ( $\mathrm{p}=0.93$ and 0.99 respectively).

Results for patient-assessed QoL over time are illustrated in Figure 2 with data before treatment and at 2, 6, 18 and 54 months. There was no significant difference between time-points in global health, cognitive function, social or emotional functioning. Physical and role (i.e. work and play activities) functioning were maintained until 18 months but were decreased at 54 months $(-10.1$ points $(\mathrm{p}=0.0002)$ and -13.2 points $(\mathrm{p}=0.003)$ respectively). Symptom scores at 54 months revealed increased fatigue $(+14$ points, $\mathrm{p}=0.003)$, dyspnoea $(+15.8$ points, $\mathrm{p}=0.002)$ and pain $(+16.2$ points, $\mathrm{p}=0.0004)$. Urinary symptoms (dysuria, increased urination frequency, incontinence, urinary retention and haematuria) worsened at 2 months $(+10$ points, $\mathrm{p}=0.0001)$ but then improved with time. The urinary symptom score was significantly higher at 54 months than immediately after IMRT but this difference was not clinically relevant as it was $<10$ points. No significant difference was recorded at any time in GI symptoms (diarrhoea, flatulence, rectitis, rectal bleeding, haemorrhoids) nor in sexual function.

In an analysis of predictive factors for QoL, risk category (D’Amico classification) was a predictive factor for global health $(\mathrm{p}=0.026)$. Hormonal treatment was not $(\mathrm{p}=0.34)$. Rectal wall volume (overall or V65) was not a predictive factor for GI symptoms. However, the V65 bladder wall volume was a predictive factor for urinary symptoms ( $\mathrm{p}=$ $0.05)$. Overall bladder wall volume and risk category were not $(\mathrm{p}=0.37$ and 0.25 , respectively).

\section{Discussion}

In this 54-month prospective study of late toxicity and QoL in prostate cancer patients treated by IMRT, no significant difference of clinical relevance was observed between baseline and 54-month scores for several items of

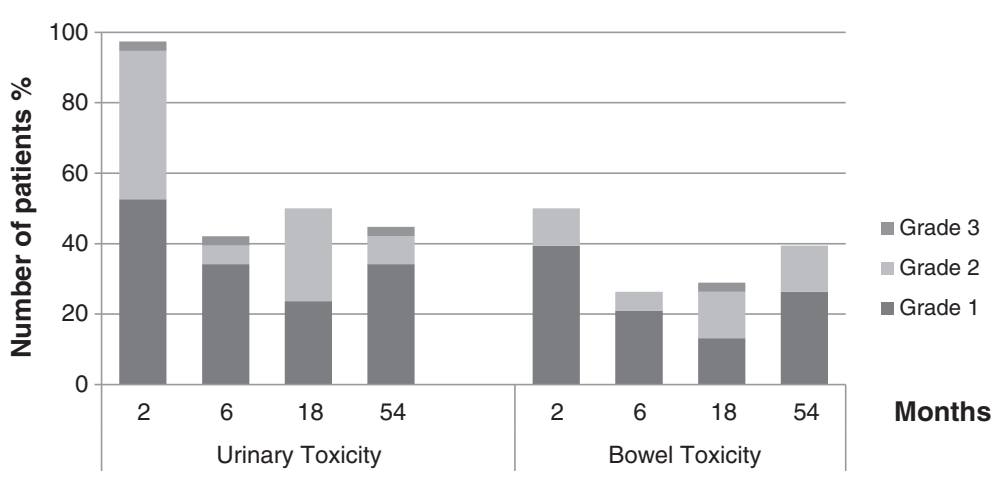

Figure 1 Physician assessment of urinary and bowel toxicity. 
Table 2 Predictive factors of late toxicity

\begin{tabular}{llr}
\hline Toxicity & Predictive factors & p \\
\hline General & Acute toxicity & NS \\
Urinary & Acute toxicity & 0.01 \\
& V65 bladder wall & NS \\
& V40 bladder wall & NS \\
& bladder wall volume & NS \\
Bowel & V65 rectal wall & 0.04 \\
& V60 rectal wall & 0.03 \\
& rectal wall volume & NS \\
\hline
\end{tabular}

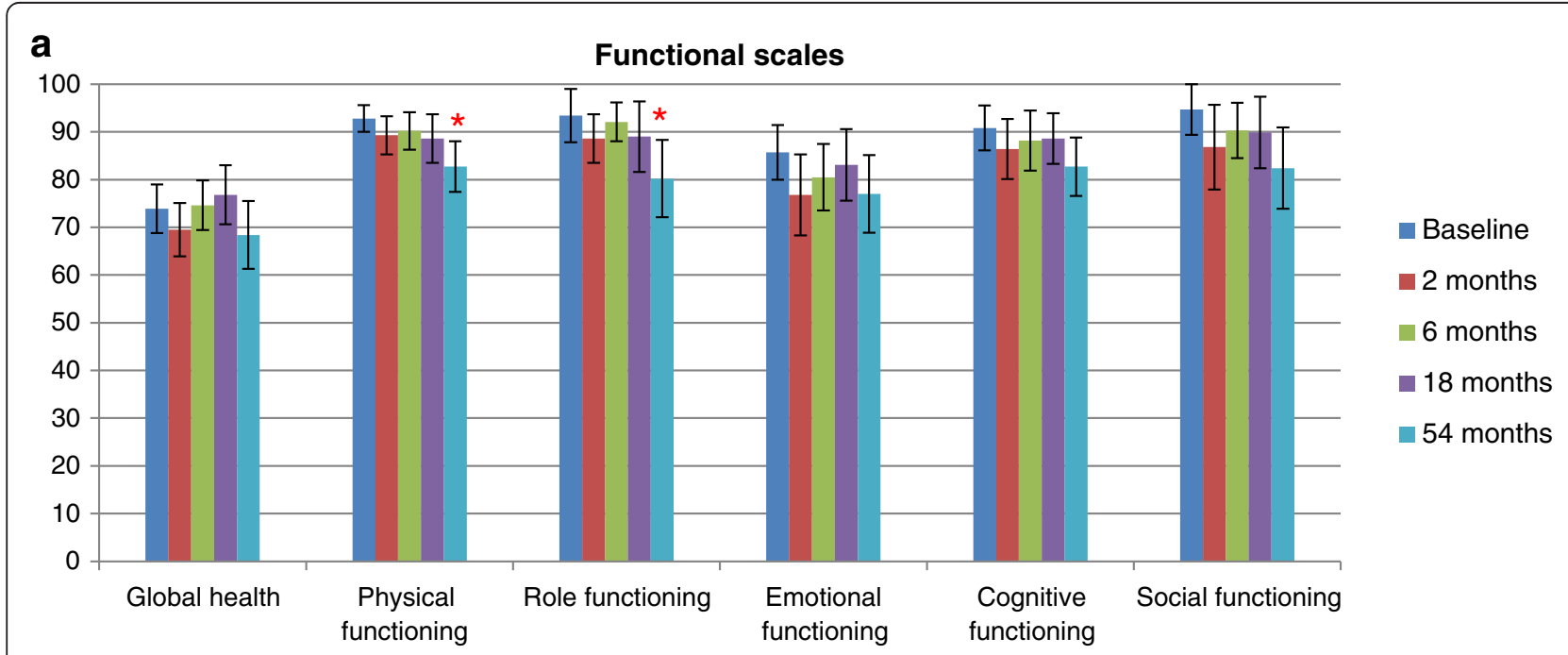

b

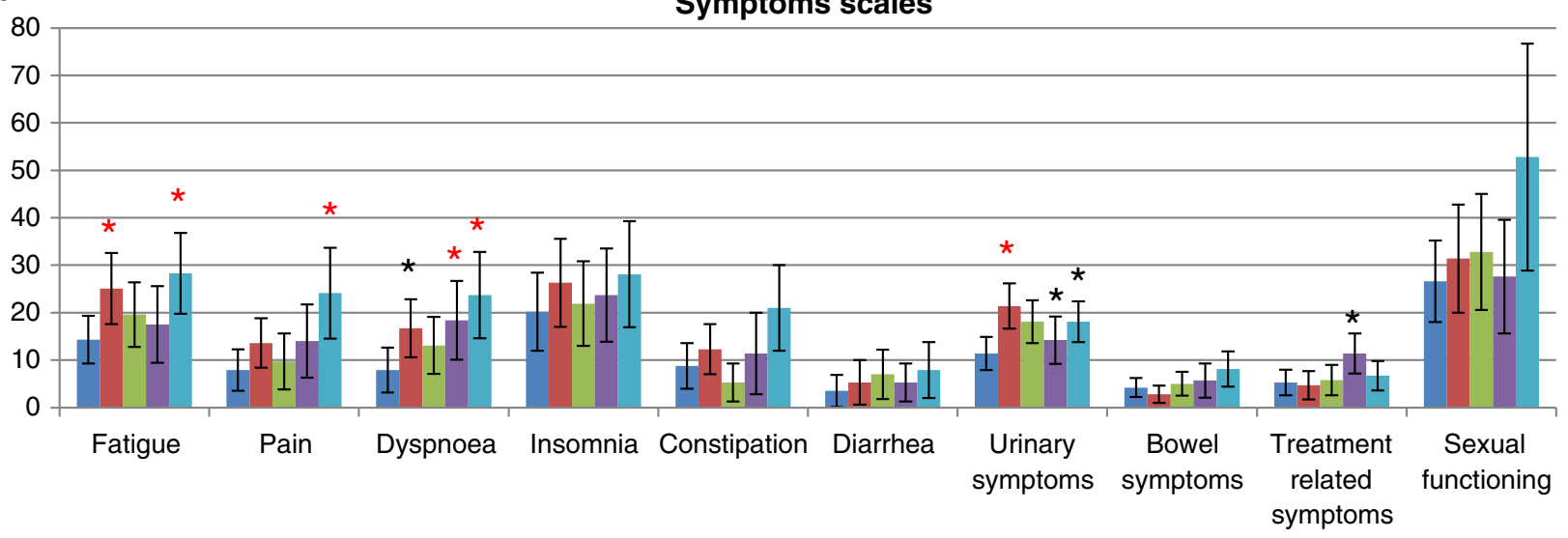

Baseline $\quad 2$ months $\quad 6$ months $\quad 18$ months $\quad 54$ months

Figure 2 Patient self-assessment of changes in quality of life over time (a) Functional scales, (b) Symptom scales. *Significant difference with baseline (Wilcoxon signed rank test, $\mathrm{p}<0.05$ ); ${ }^{*}$ (in red) Statistically significant and clinically relevant difference (>10 points).
QoL (global health, cognitive, social and emotional functioning). However, in contrast to the 3-year data in the Lips et al. study, worsening physical and role functioning was observed at 54 months, which had not been present at 18 months $[18,22]$. The worsening we observed might be related to patient age. It may not necessarily be due to the presence or absence of hormonal therapy, as has been suggested [28].

We observed temporary impairment of QoL at 2 months mainly due to urinary disorders but urinary symptom scores improved thereafter [22]. The increase in score with respect to baseline at 54 months was not clinically relevant. According to the physician assessments, by 6 months, $57.9 \%$ of patients no longer experienced any urinary toxicity and the incidence remained relatively stable until 54 months (44.7\%). According to the literature, the negative impact of urinary disorders on QoL has resolved by b

Symptoms scales 
12 months post RT [16,29], there is no difference in QoL due to urinary symptoms after IMRT without hormonal therapy compared to baseline, and urinary disorders impact less on QoL after IMRT than 3D-CRT $[18,30]$.

At 54 months, patients reported significant and clinically relevant differences with respect to baseline in unspecific symptoms such as pain, dyspnoea and fatigue but no differences in prostate cancer-specific symptoms (urinary and GI disorders). The incidence of urinary and GI toxicity 54 months after 76 Gy IMRT in our study is similar to the 5-year incidence after 70 Gy 3D-CRT in the GETUG 06 trial [8]. Grade 2+ urinary toxicity occurred in $10.5 \%$ of our patients versus $10 \%$ (70 Gy) and $17.5 \%$ ( $80 \mathrm{~Gy}$ ) in the GETUG 06 trial; Grade 2+ GI toxicity occurred in $13.2 \%$ of our patients versus $14 \%$ (70 Gy) and 19.5\% (80 Gy) patients in the GETUG 06 trial [8]. Dose escalation without enhancing toxicity is thus possible if IMRT is used instead of 3D-CRT. The results of several other studies support this conclusion: a $16 \%$ incidence of urinary toxicity and 3\% incidence of GI toxicity (grade 2+) 10 years after 81 Gy IMRT, a 9\% incidence of grade 2 urinary toxicity and a 5\% incidence of grade $2 \mathrm{GI}$ toxicity 3 years after 76 Gy IMRT, and no difference in urinary or GI toxicity between 78 Gy IMRT and 70 Gy 3D-CRT [31-33].

There were no significant and clinically relevant differences in sexual function over time, in contrast to the observations of Lips et al., but our patient numbers were too small for the assessment to be meaningful $[18,34]$. Respondent numbers were lowest immediately after IMRT $(\mathrm{n}=12)$ and at 6 months $(\mathrm{n}=12)$ (compared to $\mathrm{n}=24$ and 25 at 18 and 54 months, respectively), suggesting that recovery of sexual activity occurs only some time after treatment. Assessment of sexual function should therefore probably not be restricted to assessment of just erectile dysfunction, the commonly used objective criterion, but should also take psychological factors into consideration. In addition, assessment can be beleaguered by the fact that a decrease in libido is sometimes still a taboo subject that the practitioner may have difficulty in bringing up with some patients [35].

Like other teams, we were able to identify few factors associated with late urinary and GI toxicity and QoL, probably because we had little data available for analysis at 54 months [36]. The only predictive factor in our study was acute toxicity. In particular, hormonal therapy was not an adverse predictive factor for QoL in our study, contrary to recent findings [37]. In our initial analysis at $18 \mathrm{~m}$, ADT was associated with a worsened quality of life, especially dyspnea, insomnia, treatment related symptoms and sexual functioning. At $54 \mathrm{~m}$, only 9 patients out of 36 were still receiving ADT. This small proportion of patients probably explains why we were not able to identify an adverse QoL impact from ADT. Furthermore, Pederson et al. found that age was associated with GI toxicity and whole-pelvic IMRT with genito-urinary toxicity at 41 months, and that rectal but not bladder dose constraints were associated with toxicity [32]. However, such constraints, even though they are crucial in limiting acute toxicity, are difficult to establish because bladder and rectal filling varies between sessions [38].

The strengths of our QoL study are its prospective design and long ( $4 \frac{1}{2}$ years) follow-up. A key methodological aspect is the use of validated self-administered patient questionnaires. However, an important shortcoming is the small number of patients who completed the 54-month questionnaire owing to the deaths (unrelated to prostate cancer) or serious illnesses encountered in this aged population. There was no control arm but the prospective design enabled comparisons with baseline.

\section{Conclusion}

In conclusion, the high precision of IMRT in the treatment of localized prostate cancer enables dose escalation without engendering unacceptable toxicity [39]. There was no impairment of urinary, GI and sexual function nor of overall QoL at 54 months post IMRT. Decreased physical and role functioning were observed but may be related to ageing and comorbidities.

\section{Consent}

Written informed consent was obtained from the patient for publication of this report and any accompanying images.

Presented at the 2012 ESTRO Annual Congress, Barcelona

\section{Competing interest}

The authors declare that they have no competing interests.

\section{Authors' contribution}

$A G, V M, J R, S B, L C$, SS designed the research, AG, VM, ER, MAM and SS, performed the research, AG, VM, LC, ABA and SS analyzed the data, AG and SS wrote the paper. All authors read and approved the final manuscript.

\section{Author details}

${ }^{1}$ Integrated Center of Oncology René Gauducheau, Nantes-St Herblain, France. '2Department of Urology, Hotel Dieu Hospital, University of Nantes, Nantes, France. ${ }^{3}$ Department of Research in Psycho-oncology, Faculty of Medicine, University of Nantes, Nantes, France.

Received: 30 October 2012 Accepted: 25 February 2013 Published: 6 March 2013

\section{References}

1. D'Amico AV, Whittington R, Malkowicz SB, Schultz D, Blank K, Broderick GA Tomaszewski JE, Renshaw AA, Kaplan I, Beard CJ, Wein A: Biochemical outcome after radical prostatectomy, external beam radiation therapy, or interstitial radiation therapy for clinically localized prostate cancer. JAMA 1998, 280:969-974.

2. Hoskin PJ, Rojas AM, Bownes PJ, Lowe GJ, Ostler PJ, Bryant L: Randomised trial of external beam radiotherapy alone or combined with high-dose -rate brachytherapy boost for localised prostate cancer. Radiother Oncol 2012, 103:217-222 
3. Martin JM, Supiot S, Berthold DR: Pharmacotherapeutic management of locally advanced prostate cancer: current status. Drugs 2011, 71:1019-1041

4. Lisbona A, Averbeck D, Supiot S, Delpon G, Ali D, Vinas F, Diana C, Murariu C, Lagrange J-L: IMRT combined to IGRT: increase of the irradiated volume. Consequences? Cancer Radiother 2010, 14:563-570.

5. Crehange G, Mirjolet C, Gauthier M, Martin E, Truc G, Peignaux-Casasnovas K, Azelie C, Bonnetain F, Naudy S, Maingon P: Clinical impact of margin reduction on late toxicity and short-term biochemical control for patients treated with daily on-line image guided IMRT for prostate cancer. Radiother Oncol 2012, 103:244-246.

6. Pollack A, Zagars GK, Smith LG, Lee JJ, Von Eschenbach AC, Antolak JA, Starkschall G, Rosen I: Preliminary results of a randomized radiotherapy dose-escalation study comparing $70 \mathrm{~Gy}$ with $78 \mathrm{~Gy}$ for prostate cancer. J Clin Oncol 2000, 18:3904-3911.

7. Zietman AL, Bae K, Slater JD, Shipley WU, Efstathiou JA, Coen JJ, Bush DA, Lunt M, Spiegel DY, Skowronski R, Jabola BR, Rossi CJ: Randomized trial comparing conventional-dose with high-dose conformal radiation therapy in early-stage adenocarcinoma of the prostate: long-term results from proton radiation oncology group/american college of radiology 95-09. J Clin Oncol 2010, 28:1106-1111.

8. Beckendorf V, Guerif S, Le Prisé E, Cosset J-M, Bougnoux A, Chauvet B, Salem N, Chapet O, Bourdain S, Bachaud J-M, Maingon P, Hannoun-Levi J-M , Malissard L, Simon J-M, Pommier P, Hay M, Dubray B, Lagrange J-L, Luporsi E, Bey P: 70 Gy versus 80 Gy in localized prostate cancer: 5 -year results of GETUG 06 randomized trial. Int J Radiat Oncol Biol Phys 2011, 80:1056-1063.

9. Peeters STH, Heemsbergen WD, Koper PCM, Van Putten WLJ, Slot A, Dielwart MFH, Bonfrer JMG, Incrocci L, Lebesque JV: Dose-response in radiotherapy for localized prostate cancer: results of the Dutch multicenter randomized phase III trial comparing $68 \mathrm{~Gy}$ of radiotherapy with 78 Gy. J Clin Oncol 2006, 24:1990-1996.

10. De Meerleer GO, Vakaet LA, De Gersem WR, De Wagter C, De Naeyer B, De Neve W: Radiotherapy of prostate cancer with or without intensity modulated beams: a planning comparison. Int J Radiat Oncol Biol Phys 2000, 47:639-648.

11. Peeters STH, Heemsbergen WD, Van Putten WLJ, Slot A, Tabak H, Mens JW, Lebesque JV, Koper PCM: Acute and late complications after radiotherapy for prostate cancer: results of a multicenter randomized trial comparing 68 Gy to 78 Gy. Int J Radiat Oncol Biol Phys 2005, 61:1019-1034.

12. Zelefsky MJ, Chan H, Hunt M, Yamada Y, Shippy AM, Amols H: Long-term outcome of high dose intensity modulated radiation therapy for patients with clinically localized prostate cancer. J Urol 2006, 176:1415-1419.

13. Zelefsky MJ, Levin EJ, Hunt M, Yamada Y, Shippy AM, Jackson A, Amols HI: Incidence of late rectal and urinary toxicities after three-dimensional conformal radiotherapy and intensity-modulated radiotherapy for localized prostate cancer. Int J Radiat Oncol Biol Phys 2008, 70:1124-1129.

14. Niezgoda HE, Pater $J$ : A validation study of the domains of the core EORTC quality of life questionnaire. Qual Life Res 1993, 2:319-325.

15. Ferrer M, Suárez JF, Guedea F, Fernández P, Macías V, Mariño A, Hervas A, Herruzo I, Ortiz MJ, Villavicencio H, Craven-Bratle J, Garin O, Aguiló F: Health-related quality of life 2 years after treatment with radical prostatectomy, prostate brachytherapy, or external beam radiotherapy in patients with clinically localized prostate cancer. Int J Radiat Oncol Biol Phys 2008, 72:421-432.

16. Sanda MG, Dunn RL, Michalski J, Sandler HM, Northouse L, Hembroff L, Lin X, Greenfield TK, Litwin MS, Saigal CS, Mahadevan A, Klein E, Kibel A, Pisters LL, Kuban D, Kaplan I, Wood D, Ciezki J, Shah N, Wei JT: Quality of life and satisfaction with outcome among prostate-cancer survivors. N Engl J Med 2008, 358:1250-1261.

17. Litwin MS, Sadetsky N, Pasta DJ, Lubeck DP: Bowel function and bother after treatment for early stage prostate cancer: a longitudinal quality of life analysis from CaPSURE. J Urol 2004, 172:515-519.

18. Lips IM, Van Gils CH, Van der Heide UA, Kruger AEB, Van Vulpen M: Healthrelated quality of life 3 years after high-dose intensity-modulated radiotherapy with gold fiducial marker-based position verification. BJU Int 2009, 103:762-767.

19. Namiki S, Ishidoya S, Ito A, Tochigi T, Numata I, Narazaki K, Yamada S, Takai $Y$, Arai Y: Five-year follow-up of health-related quality of life after intensity-modulated radiation therapy for prostate cancer. Jpn J Clin Oncol 2009, 39:732-738.
20. Odrazka K, Dolezel M, Vanasek J, Vaculikova M, Zouhar M, Sefrova J, Paluska P, Vosmik M, Kohlova T, Kolarova I, Macingova Z, Navratil P, Brodak M, Prosvic $P$ : Time course of late rectal toxicity after radiation therapy for prostate cancer. Prostate Cancer Prostatic Dis 2010, 13:138-143.

21. Sharma NK, Li T, Chen DY, Pollack A, Horwitz EM, Buyyounouski MK: Intensity-modulated radiotherapy reduces gastrointestinal toxicity in patients treated with androgen deprivation therapy for prostate cancer. Int J Radiat Oncol Biol Phys 2011, 80:437-444.

22. Marchand V, Bourdin S, Charbonnel C, Rio E, Munos C, Campion L, Bonnaud-Antignac A, Lisbona A, Mahé M-A, Supiot S: No impairment of quality of life 18 months after high-dose intensity-modulated radiotherapy for localized prostate cancer: a prospective study. Int Radiat Oncol Biol Phys 2010, 77:1053-1059.

23. Partin AW, Kattan MW, Subong EN, Walsh PC, Wojno KJ, Oesterling JE, Scardino PT, Pearson JD: Combination of prostate-specific antigen, clinical stage, and Gleason score to predict pathological stage of localized prostate cancer. A multi-institutional update. JAMA 1997, 277:1445-1451.

24. Delpon G, Llagostera C, Le Blanc M, Rio E, Supiot S, Mahé M-A, Lisbona A: [Use of IGRT for prostate cancers (OBI-CBCT Varian, ExacTrac BrainLAB and MVCT TomoTherapy)]. Cancer Radiother 2009, 13:399-407.

25. Aaronson NK, Ahmedzai S, Bergman B, Bullinger M, Cull A, Duez NJ, Filiberti A, Flechtner H, Fleishman SB, De Haes JC: The European Organization for Research and Treatment of Cancer QLQ-C30: a quality-of-life instrument for use in international clinical trials in oncology. J Natl Cancer Inst 1993, 85:365-376

26. Fayers P, Bottomley A: Quality Of life research within the EORTC-the EORTC QLQ-C30. European organisation for research and treatment of cancer. Eur J Cancer 2002, 38(Suppl 4):S125-S133.

27. Osoba D, Rodrigues G, Myles J, Zee B, Pater J: Interpreting the significance of changes in health-related quality-of-life scores. J Clin Oncol 1998, 16:139-144.

28. Grant JD, Litwin MS, Kwan L, Lee SP, Steinberg ML, King CR: Does hormone therapy exacerbate the adverse effects of radiotherapy in men with prostate cancer? A quality of life study. J Urol 2011, 185:1674-1680.

29. Chen RC, Zhang Y, Chen M-H, McMahon E, Loffredo M, McPherson CP, Nguyen AU, Nguyen PL, D'Amico AV: Patient-reported quality of life during radiation treatment for localized prostate cancer: results from a prospective phase II trial. BJU Int 2012, 110(11):1690-1695.

30. Namiki S, Ishidoya S, Tochigi T, Kawamura S, Kuwahara M, Terai A Yoshimura K, Numata I, Satoh M, Saito S, Takai Y, Yamada S, Arai Y: Healthrelated quality of life after intensity modulated radiation therapy for localized prostate cancer: comparison with conventional and conformal radiotherapy. Jpn J Clin Oncol 2006, 36:224-230.

31. Odrazka K, Dolezel M, Vanasek J, Vaculikova M, Zouhar M, Sefrova J, Paluska P, Vosmik M, Kohlova T, Kolarova I, Navratil P, Brodak M, Prosvic P, Hoffmann $P$ : Late toxicity after conformal and intensity-modulated radiation therapy for prostate cancer: impact of previous surgery for benign prostatic hyperplasia. Int J Urol 2010, 17:784-790.

32. Pederson AW, Fricano J, Correa D, Pelizzari CA, Liauw SL: Late toxicity after intensity-modulated radiation therapy for localized prostate cancer: an exploration of dose-volume histogram parameters to limit genitourinary and gastrointestinal toxicity. Int J Radiat Oncol Biol Phys 2010, 82(1):235-241.

33. Alicikus ZA, Yamada Y, Zhang Z, Pei X, Hunt M, Kollmeier M, Cox B, Zelefsky MJ: Ten-year outcomes of high-dose, intensity-modulated radiotherapy for localized prostate cancer. Cancer 2011, 117:1429-1437.

34. Choo R, Long J, Gray R, Morton G, Gardner S, Danjoux C: Prospective survey of sexual function among patients with clinically localized prostate cancer referred for definitive radiotherapy and the impact of radiotherapy on sexual function. Support Care Cancer 2010, 18:715-722.

35. Forbat L, White I, Marshall-Lucette S, Kelly D: Discussing the sexual consequences of treatment in radiotherapy and urology consultations with couples affected by prostate cancer. BJU Int 2011, 109(1):98-103.

36. Vesprini D, Sia M, Lockwood G, Moseley D, Rosewall T, Bayley A, Bristow R, Chung P, Ménard C, Milosevic M, Warde P, Catton C: Role of principal component analysis in predicting toxicity in prostate cancer patients treated with hypofractionated intensity-modulated radiation therapy. Int J Radiat Oncol Biol Phys 2011, 81:e415-e421.

37. Denham JW, Wilcox C, Joseph D, Spry NA, Lamb DS, Tai K-H, Matthews J, Atkinson C, Turner S, Christie D, Gogna NK, Kenny L, Duchesne G, Delahunt $B$, McElduff P: Quality of life in men with locally advanced prostate cancer treated with leuprorelin and radiotherapy with or without 
zoledronic acid (TROG 03.04 RADAR): secondary endpoints from a randomised phase 3 factorial trial. Lancet Oncol 2012, 13:1260-1270.

38. Pinkawa M, Fischedick K, Asadpour B, Gagel B, Piroth MD, Eble MJ: Lowgrade toxicity after conformal radiation therapy for prostate cancerimpact of bladder volume. Int J Radiat Oncol Biol Phys 2006, 64:835-841.

39. Eade TN, Guo L, Forde E, Vaux K, Vass J, Hunt P, Kneebone A: Image-guided dose-escalated intensity-modulated radiation therapy for prostate cancer: treating to doses beyond 78 Gy. BJU Int 2011, 109(11):1655-1660.

doi:10.1186/1748-717X-8-53

Cite this article as: Goineau et al:: Prospective evaluation of quality of life 54 months after high-dose intensity-modulated radiotherapy for localized prostate cancer. Radiation Oncology 2013 8:53.

\section{Submit your next manuscript to BioMed Central and take full advantage of:}

- Convenient online submission

- Thorough peer review

- No space constraints or color figure charges

- Immediate publication on acceptance

- Inclusion in PubMed, CAS, Scopus and Google Scholar

- Research which is freely available for redistribution 